University of Nebraska - Lincoln

DigitalCommons@University of Nebraska - Lincoln

Papers in Veterinary and Biomedical Science

Veterinary and Biomedical Sciences

Department of

$12-10-2007$

\title{
Porcine intestinal epithelial cell lines as a new in vitro model for studying adherence and pathogenesis of enterotoxigenic Escherichia coli
}

\author{
Seung Y. Koh \\ South Dakota State University \\ Sajan George \\ South Dakota State University \\ Volker Brozel \\ South Dakota State University \\ Rodney A. Moxley \\ University of Nebraska-Lincoln, rmoxley1@unl.edu \\ David H. Francis \\ South Dakota State University, david.francis@sdstate.edu \\ See next page for additional authors
}

Follow this and additional works at: https://digitalcommons.unl.edu/vetscipapers

Part of the Veterinary Medicine Commons

Koh, Seung Y.; George, Sajan; Brozel, Volker; Moxley, Rodney A.; Francis, David H.; and Kaushik, Radhey, "Porcine intestinal epithelial cell lines as a new in vitro model for studying adherence and pathogenesis of enterotoxigenic Escherichia coli" (2007). Papers in Veterinary and Biomedical Science. 92.

https://digitalcommons.unl.edu/vetscipapers/92

This Article is brought to you for free and open access by the Veterinary and Biomedical Sciences, Department of at DigitalCommons@University of Nebraska - Lincoln. It has been accepted for inclusion in Papers in Veterinary and Biomedical Science by an authorized administrator of DigitalCommons@University of Nebraska - Lincoln. 


\section{Authors}

Seung Y. Koh, Sajan George, Volker Brozel, Rodney A. Moxley, David H. Francis, and Radhey Kaushik 


\title{
Porcine intestinal epithelial cell lines as a new in vitro model for studying adherence and pathogenesis of enterotoxigenic Escherichia coli
}

\author{
Seung Y. Koh a, Sajan George ${ }^{\text {b, c }}$, Volker Brözel ${ }^{\text {b, c }}$, Rodney Moxley ${ }^{\mathrm{d}}$, \\ David Francis ${ }^{a, c}$, and Radhey S. Kaushik ${ }^{\text {a, b, c }}$ \\ ${ }^{a}$ Department of Veterinary Science, \\ South Dakota State University, Brookings, SD 57007, USA \\ ${ }^{\mathrm{b}}$ Department of Biology and Microbiology, \\ South Dakota State University, Brookings, SD 57007, USA \\ ${ }^{\mathrm{c}}$ Center for Infectious Disease Research and Vaccinology (CIDRV), \\ South Dakota State University, Brookings, SD 57007, USA \\ ${ }^{\mathrm{d}}$ Department of Veterinary and Biomedical Sciences, \\ University of Nebraska-Lincoln, Lincoln, NE 68583, USA \\ Corresponding author: R. S. Kaushik, SNP 252A, P.O. Box 2140D, \\ Department of Biology and Microbiology, South Dakota State University, \\ Brookings, SD 57007, USA. Tel. 605 688-5501; fax 605 688-5624; \\ email radhey.kaushik@sdstate.edu
}

\begin{abstract}
Enterotoxigenic Escherichia coli (ETEC) infections result in large economic losses in the swine industry worldwide. The organism causes diarrhea by adhering to and colonizing enterocytes in the small intestines. While much progress has been made in understanding the pathogenesis of ETEC, no homologous intestinal epithelial cultures suitable for studying porcine ETEC pathogenesis have been described prior to this report. In the current study, we investigated the adherence of various porcine ETEC strains to two porcine (IPEC-1 and IPEC-J2) and one human (INT-407) small intestinal epithelial cell lines. Each cell line was assessed for its ability to support the adherence of $E$. coli expressing fimbrial adhesins K88ab, K88ac, K88ad, K99, F41, 987P, and F18. Wild-type ETEC expressing K88ab, K88ac, and K88ad efficiently bound to both IPEC-1 and IPEC-J2 cells. An ETEC strain expressing both K99 and F41 bound heavily to both porcine cell lines but an $E$. coli strain expressing only K99 bound very poorly to these cells. $E$. coli expressing F18 adhesin strongly bound to IPEC-1 cells but did not adhere to IPEC-J2 cells. The E. coli strains G58-1 and 711 which express no fimbrial adhesins and those that express $987 \mathrm{P}$ fimbriae failed to bind to either porcine cell line. Only strains B41 and K12:K99 bound in abundance to INT-407 cells. The binding of porcine ETEC to IPEC-J2, IPEC-1 and INT-407 with varying affinities, together with lack of binding of 987 P ETEC and non-fimbriated E. coli strains, suggests strain-specific E. coli binding to these cell lines. These findings suggest the potential usefulness of porcine intestinal cell lines for studying ETEC pathogenesis.
\end{abstract}

Keywords: porcine, enterotoxigenic Escherichia coli, intestinal epithelial cells, adherence, pathogenesis 


\section{Introduction}

Both porcine neonatal and post-weaning diarrhea (PWD) caused by enterotoxigenic Escherichia coli (ETEC) result in significant morbidity and mortality and are economically important diseases of pigs (Fairbrother et al., 2005; Nagy and Fekete, 2005). The colonization of ETEC in the small intestine is primarily mediated by fimbria which confer to ETEC the ability to attach to receptors on the enterocytes. Secretory diarrhea associated with ETEC infection is mediated by any of several enterotoxins which include heat labile enterotoxin (LT), heat stable enterotoxin-a (STa), and enterotoxinb (STb). The most common adhesins of porcine ETEC include K88 (F4) (Jones and Rutter, 1972), K99 (F5) (Moon et al., 1977), 987P (F6) (Isaacson et al., 1978), F18 (Imberechts et al., 1996), and F41 (Morris et al., 1982). Three serological antigenic variants of K88 fimbrae exist, K88ab, K88ac, and K88ad (Gaastra and Pederson, 1986), and K88ac is the most prevalent and clinically important variant ETEC strain isolated from diarrheic pigs (Fairbrother et al., 2005; Francis et al., 1998; Nagy and Fekete, 2005).
A number of cellular systems had been used to study the adherence of ETEC, including erythrocytes (Evans et al., 1979), primary enterocytes (Knutton et al., 1984), brush border vesicles (Baker et al., 1997), and human tumor cell lines (Roselli et al., 2006). None of these cellular systems are highly suitable for porcine ETEC pathogenesis studies. The objective of this study was to examine the adherence of various strains of ETEC to two porcine intestinal epithelial cell lines IPEC-J2 and IPEC-1 and to compare their adherence to the human intestinal epithelial cell line INT-407. The findings of this study indicate that IPEC-J2 and IPEC-1 cell lines are superior to the human intestinal cell line (INT-407) in that they support the adherence of most porcine ETEC strains.

\section{Materials and methods}

\subsection{Bacterial strains}

All E. coli strains used in this study are listed, and their phenotypes described in Table 1 . These strains were cultured on $5 \%$ sheep blood agar (brain heart

Table 1. Bacterial strains used for the cell adhesion assay

\begin{tabular}{|c|c|c|}
\hline E. coli strains & Relevant properties & References \\
\hline 263 & Wild-type 08:K87:K88ab ETEC, LT+, STb+ & (Moon et al., 1968) \\
\hline 1476 & Laboratory construct K12:K88ab & (Baker et al., 1997) \\
\hline F962 & K12: K88ab 5K, ampr, pFM2O5 & (Bakker et al., 1992) \\
\hline $3030-2$ & Wild-type O157:K87:K88ac ETEC, LT+, STb+ & (Francis and Willgohs, 1991) \\
\hline K12:K88ac & Laboratory construct K12:K88ac ${ }^{\mathrm{a}}$ & (Baker et al., 1997) \\
\hline F783 = F963 & K12:K88ac C6oo amp ${ }^{\mathrm{r}}$, pDB88-102 & (Bakker et al., 1992) \\
\hline $1836-2$ & Wild-type K88ac+; LT-, ST-, astA+ & (Zhang et al., 2006) \\
\hline $2534-86$ & Wild-type 08:K87:NM: K88ac LT-I+, STb+ & (Moxley et al., 1998) \\
\hline WAM 2317 & Nalidixic acid-resistant mutant of 2534-86, LT-I+, STb+ & (Berberov et al., 2004) \\
\hline MUN 285 & Mutant of WAM 2317, LT-I- & (Berberov et al., 2004) \\
\hline MUN 287 & $\mathrm{Nal}^{\mathrm{r}} \mathrm{Km}^{\mathrm{r}}$, LT-I+ complemented strain & (Berberov et al., 2004) \\
\hline Morris & Wild-type O8:K87:K88ad ETEC, LT+, STb+ & (Baker et al., 1997) \\
\hline K12:K88ad & Laboratory construct K12:K88ad & (Baker et al., 1997) \\
\hline F291 & K12:K88ad 5K, amp ${ }^{\mathrm{r}}, \mathrm{pBad} 1$ & (Gaastra and Pederson, 1986) \\
\hline 2134 & Wild-type, O157:H19:F18ac, 4P-, STa+, STb+ & (Casey et al., 1992) \\
\hline K12:K99 & Laboratory construct K12:K99 ${ }^{\mathrm{a}}$ & (Moon et al., 1977) \\
\hline B41 & Wild-type, O101:K99; F41; STa+ & (Orskov et al., 1975) \\
\hline 1194 & Wild-type, O141:987P, STa+, STb+ & (Mullaney et al., 1991) \\
\hline G58-1 & Non-pathogenic wild-type, O101:K28:NM non-fimbriated, LT- & (Francis et al., 1986) \\
\hline 711 & K12:K88-negative parent of laboratory constructs. & (Baker et al., 1997) \\
\hline
\end{tabular}

${ }^{\text {a }}$ Wild-type plasmid was introduced by conjugation. 
infusion base), except K12:K99 which was grown on Essential Salt Medium (Francis et al., 1982) supplemented with Eagle's essential amino acids and vitamins. The bacterial cultures were incubated for $18 \mathrm{~h}$ at $32{ }^{\circ} \mathrm{C}$ before use in the adherence studies.

\subsection{Cell lines and culture conditions}

The IPEC-J2 and IPEC-1 cell lines have been previously described (Lu et al., 2002; Schierack et al., 2006). These undifferentiated porcine intestinal epithelial cell lines were derived from jejunum and small intestine respectively, from un-suckled 1-dayold piglets. Neither of these cell lines was immortalized and therefore they represent a better model of normal porcine intestinal epithelium than transformed cell lines. Both IPEC-J2 and IPEC-1 cells were seeded on plastic cell culture flasks $\left(25 \mathrm{~cm}^{2}\right.$, Corning, NY). These cell lines were cultured and maintained in Dulbecco's Modified Eagle Medium (DMEM)-Hank F12 (GIBCO, Invitrogen Corporation, Grand Island, NY) supplemented with $5 \%$ fetal calf serum (FCS; Atlanta Biologicals, Lawrenceville, $\mathrm{GA})$, penicillin $(100 \mathrm{IU} / \mathrm{ml})$, streptomycin $(100 \mu \mathrm{g} /$ $\mathrm{ml})$ (Invitrogen), insulin $(5 \mu \mathrm{g} / \mathrm{ml})$, transferrin $(5 \mu \mathrm{g} / \mathrm{ml})$, selenium ( $5 \mathrm{ng} / \mathrm{ml}$ ) (ITS Premix; Sigma, St. Louis, MI), and $5 \mathrm{ng} / \mathrm{ml}$ of epidermal growth factor (EGF; Sigma), hereafter, referred as IPEC media. The stock culture of INT-407 (ATCC, CCL-6), a non-transformed human embryonic intestinal epithelial cell line, was obtained from American Type Culture Collection (ATCC, Manassas, VA). INT407 cells were cultured and maintained in DMEM (GIBCO, Invitrogen) supplemented with 10\% FCS, l-glutamine $(2 \mu \mathrm{M})$, penicillin $(100 \mathrm{IU} / \mathrm{ml})$, streptomycin $(100 \mu \mathrm{g} / \mathrm{ml})$, and amphotericin $(25 \mu \mathrm{g} /$ ml) (Mediatech, Herndon, VA), hereafter, referred as DMEM-10. The cultures were maintained in a humidified incubator in an atmosphere of $5 \% \mathrm{CO}_{2}$ and $95 \%$ air at $37^{\circ} \mathrm{C}$. After 4 to 5 days of culturing, all the three types of cultured cells became confluent. Cell monolayers were washed with phosphate buffered saline (PBS) and trypsinized with $1 \times$ trypsin-EDTA (Mediatech). The detached cells were pelleted at $200 \times g$ for 5 min, re-suspended in antibiotic-free medium, and used for the adherence assays. The continuous cultures of epithelial cell lines were maintained by seeding culture flasks at 1:3 ratios at each passage.

\subsection{Polarized IPEC-J2 cells}

The IPEC-J2 cells were differentiated and polarized on collagen-coated permeable supports in serum-free medium. Two million IPEC-J2 cells harvested from confluent culture flasks $\left(25 \mathrm{~cm}^{2}\right)$ were seeded on a 24-mm diameter (growth area $4.7 \mathrm{~cm}^{2}$ ) collagen-coated transwell permeable support filter (3.0 $\mu \mathrm{m}$ pore size). Two $\mathrm{ml}$ of IPEC medium was added to the upper chamber while $3 \mathrm{ml}$ of the medium was added to the bottom of wells in a 6-well transwell culture plate (Corning). The cells were maintained in serum-containing medium for $48 \mathrm{~h}$ and then switched to the same medium containing $10^{-7} \mathrm{M}$ dexamethasone (Sigma) without FCS to minimize cell growth and enhance differentiation. The medium was changed every second day until cells showed features of polarization as judged by a significant increase in trans-epithelial electrical resistance (TER) (Schierack et al., 2006). Cell cultures showing TER values between 2000 and $5500 \Omega \mathrm{cm}^{2}$ were used for adherence assays.

\subsection{Bacterial adherence assays}

Fimbriae-mediated binding specificity of various $E$. coli strains was determined by a cell adhesion assay. The cell lines IPEC-J2 (passage 42-52), IPEC-1 (passage 25-30), and INT-407 (passage 12-16) were used for this study. The adherence assay procedure was described previously (Baker et al., 1997). Briefly, E. coli were cultured overnight on $5 \%$ sheep blood agar plates at $32{ }^{\circ} \mathrm{C}$. Bacterial cells were suspended in sterile PBS to achieve an optical density of approximately 1.0 at $520 \mathrm{~nm}$. Fifty microliters $(50 \mu \mathrm{l})$ of $E$. coli suspension was added to a plate well followed by addition of a suspension of porcine/human intestinal epithelial cells $\left(\sim 5 \times 10^{4}\right.$ cells $)$ in PBS containing $4 \%$ of D-Mannose (to prevent binding by Type I fimbriae if present). These suspensions were mixed for 20 min with rotational agitation at $140 \mathrm{rpm}$ and then incubated for an additional $4 \mathrm{~h}$ at $4{ }^{\circ} \mathrm{C}$. ETEC binding to epithelial cells was observed by phase contrast microscopy and bright field microscopy under oil (1000× magnification), and extent of bacterial binding to the epithelial cells was determined. The relative number of bacteria binding to epithelial cells was judged and rated $(-=$ no adherent bacteria; $+=$ few bound bacteria, $++=$ several to a moderate number of bacteria bound; $+++=$ large num- 
bers of bacteria bound). Each adherence assay was repeated three times or more with each cell line $(8 \times$ with IPEC-J2, $3 \times$ with IPEC-1, and $4 \times$ with INT407) to confirm the consistency of results. In some assays, in order to ascertain the viability of adherent ETEC, parallel bacterial suspensions were stained with Live/Dead ${ }^{\circledR}$ BacLight $^{\mathrm{TM}}$ stain (Invitrogen, CA, USA) with live cells fluorescing green and dead cells fluorescing red. Bacterial adherence was observed by fluorescence microscopy using an $\mathrm{AX} 70$ fluorescence microscope (Olympus).

\subsection{Green fluorescence protein-tagged E. coli}

To enhance the visualization of bacterial adherence and confirm the findings obtained using unlabelled ETEC, the confluently binding strain B41 was transformed to express eGFP from plasmid pGLO (BioRad, Hercules, CA). The eGFP gene is under the control of an arabinose-inducible promoter. Strain B41 was made chemically competent by standard methods (Sambrook et al., 2001) and transformed by heat shock with pGLO as per the manufacturer's instructions. Transformants were selected by plating on an LB agar plate containing ampicillin $(50 \mu \mathrm{g} /$ $\mathrm{ml})$ and arabinose $(6 \mathrm{mg} / \mathrm{ml})$, and incubated overnight at $37^{\circ} \mathrm{C}$. Successfully transformed colonies fluoresced green upon UV excitation. Transformants to be used in adherence assays were cultured overnight on sheep blood agar amended with arabinose $(6 \mathrm{mg} / \mathrm{ml})$. The adherence assay was performed as described above. Cells were viewed by confocal scanning laser microscopy (CSLM) using an Olympus Fluoview FV30o Laser Scanning Confocal Microscope System interfaced with an inverted-microscope (Olympus IX70) using Blue Argon (488 nm) and Green Helium Neon (543 nm) excitation lasers.

\section{Results}

Both porcine small intestinal epithelial cell lines bound a range of ETEC, albeit to varying degrees. Representative photomicrographs indicating the degree of adherent bacteria are shown in Figure 1A and

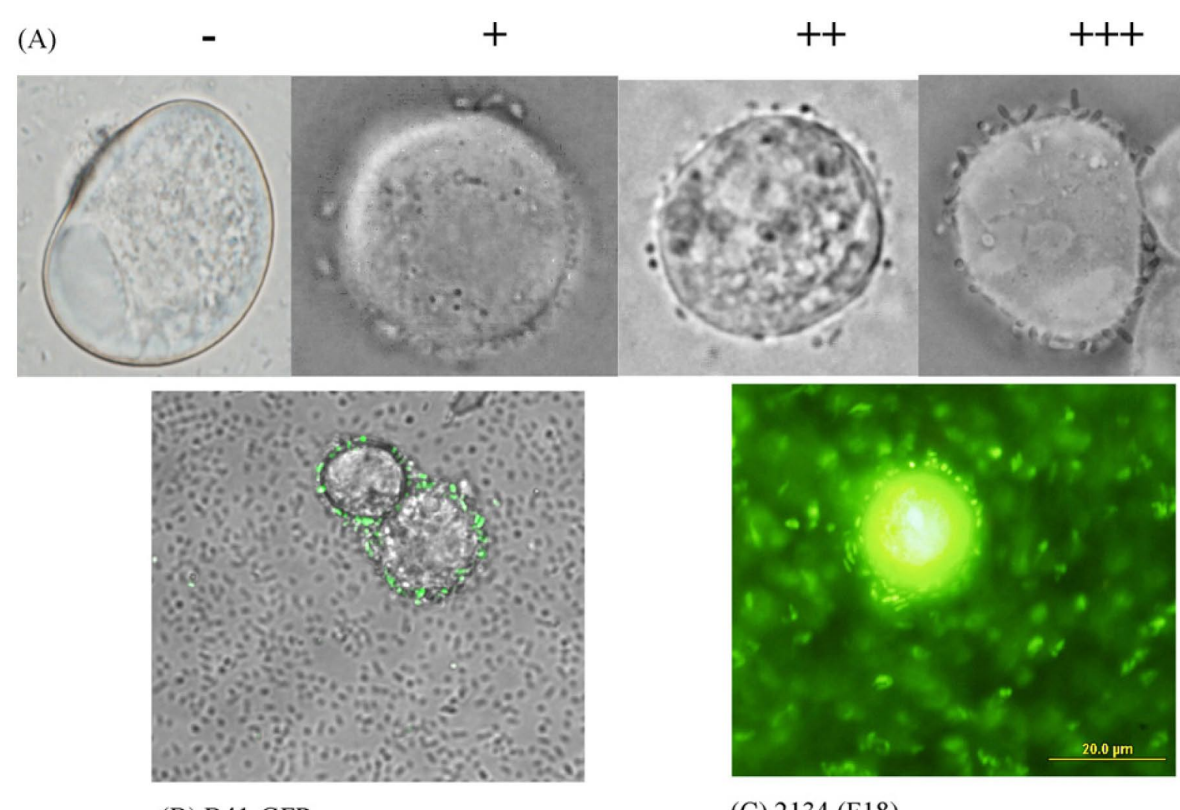

(B) B41-GFP

(C) 2134 (F18)

Figure 1. Adherence of $E$. coli strains to IPEC-J2 and IPEC-1 cells. (A) Shows the degree of $E$. coli binding to porcine intestinal epithelial cells. Final magnifications $1000 \times$. - : No binding of bacteria; +: few bacteria bound per cell; ++: several bacteria bound per cell and +++: large numbers of bacteria bound per cell. GFP-transformed bacteria and BacLight dye were used to enhance the bacterial visualization. (B) The confocal image showed GFP-transformed bacterial (ETEC strain B41) attachment to IPEC-J2 cells. (C) ETEC F18 strain 2134 intensively bound to IPEC-1 cells. All bacterial cells attached to the IPEC-1 cell were live cells. 
Table 2. Results of adherence assays with pig intestinal epithelial cell lines using ETEC and laboratory constructs

\begin{tabular}{|c|c|c|c|c|}
\hline Strains & Adhesin & IPEC-J2 cells & IPEC- 1 cells & INT-407 cells \\
\hline $263^{\mathrm{a}}$ & K88ab & ++ or +++ & +++ & + \\
\hline K12:K88ab & K88ab & +++ & +++ & + \\
\hline F962 & K88ab & + or ++ & +++ & + \\
\hline 3030-2 ${ }^{\mathrm{a}}$ & K88ac & +++ & ++ or +++ & ++ \\
\hline K12:K88ac & K88ac & + & ++ or +++ & + \\
\hline F783 & K88ac & + & ++ & - \\
\hline $1836-2^{a}$ & K88ac & + & ++ & - \\
\hline $2534-86^{a}$ & K88ac & ++ or +++ & ++ or +++ & ++ or +++ \\
\hline WAM 2317 & K88ac & ++ & ++ or +++ & ++ or +++ \\
\hline MUN 287 & K88ac & ++ or +++ & ++ or +++ & ++ or +++ \\
\hline MUN 285 & K88ac & ++ or +++ & +++ & ++ or +++ \\
\hline Morris $^{\mathrm{a}}$ & K88ad & +++ & +++ & ++ or +++ \\
\hline K12:K88ad & K88ad & + or ++ & +++ & - \\
\hline F291 & K88ad & + or +++ & +++ & - \\
\hline $1194^{\mathrm{a}}$ & $987 \mathrm{P}$ & - & - & - \\
\hline $2134^{\mathrm{a}}$ & F18 & - & +++ & - \\
\hline B441 ${ }^{\mathrm{a}}$ & K99, F41 & +++ & +++ & +++ \\
\hline K12:K99 & K99 & + & + & +++ \\
\hline G58-1 & None & - & - & - \\
\hline 711 & None & - & - & - \\
\hline
\end{tabular}

${ }^{a}$ Wild-type strains are indicated in bold.

the results of adherence assays are summarized in Table 2. Wild-type E. coli strains 263, 3030-2, and Morris expressing K88ab, K88ac, or K88ad fimbriae strongly bound to both IPEC-J2 and IPEC-1 cells. $E$. coli strain B41 expressing both K99 and F41 fimbria heavily bound to all three epithelial cell lines (IPEC1, IPEC-J2, and INT-407). The laboratory construct K12:K99 bound poorly to either IPEC-J2 or IPEC1 cells when compared to the binding of the B41 strain, but heavily bound to INT-407.

The $E$. coli strain 2134 expressing F18 bound only to IPEC-1 cells. However, E. coli that expressed $987 \mathrm{P}$ failed to bind any of the cell lines. In addition, non-fimbriated $E$. coli strains G58-1 and 711 failed to bind cells of any of the three cell lines we examined. Polarization of IPEC-J2 cells did not result in the appearance of binding patterns that differed from those of non-polarized cells (data not shown).

Wild-type E. coli K88ac strain 3030-2 bound in greater abundance to IPEC-J2 cells than did laboratory constructs $\mathrm{K} 12: \mathrm{K} 88 \mathrm{ac}$ and F783, which expressed the same fimbrial antigens. The K88acpositive but toxin-negative wild-type strain 1836-2 showed very limited binding to both IPEC-1 and IPEC-J2 cells. However, wild-type K88ac strain 2534-86 and its nalidixic acid-resistant (NalR) mu- tant (WAM2317) and LT- mutant derivative of WAM2317 (MUN285) mutants adhered to both porcine cell types (IPEC-J2 and IPEC-1) and human cell line INT-407 with similar efficiencies (Table 2). Wildtype strains expressing K88ab and K88ad bound in abundance to IPEC-J2, but K88ab and K88ad laboratory constructs bound in small numbers to these cells. However, these wild-type strains and laboratory constructs bound equally to IPEC-1 cells.

Adherence assays with GFP-tagged bacteria (B41) were also conducted and their adherence to all the three cell lines was observed using confocal scanning laser microscopy (Figure 1B). Similar adherence patterns as observed with GFP-negative bacteria (Table 2) were detected. BacLight staining was used in the adherence assays with ETEC F18 strain 2134 to enhance the visualization of bacterial adherence and differentiate between live and dead bacteria. All the attached bacterial cells fluoresced green indicating that they were live (Figure $1 \mathrm{C}$ ).

\section{Discussion}

In this study all three K88+ ETEC strains (K88ab, K88ac, and K88ad) adhered to both IPEC-J2 and 
IPEC-1 cells, and the degree of ETEC adherence to these cells was strain-specific. Adhesin-negative $E$. coli strains G-58-1 and 711 did not adhere to any of three cell lines tested in this study. Furthermore, ETEC strains expressing K99 and 987P fimbria did not adhere to IPEC-J2 and IPEC-1 cells. Not surprisingly, most porcine ETEC strains bound better to porcine epithelial cells than to INT-407 cells. The K99+ ETEC strain was the exception to this general finding as it bound extensively to INT-407 and not to either porcine cell line. Overall, IPEC-1 cells were superior to IPEC-J2 cells in ETEC binding, both in terms of the types of adhesins that bound to these cells and the intensity of bacterial binding (Table 2). In general, the observations of this study suggest that IPEC-J2 and IPEC-1 strongly support the adhesion of porcine ETEC and may be a suitable model for studying some aspects of ETEC pathogenesis.

In this study, higher numbers of K88ac bacteria of wild-type strain 3030-2 bound to IPEC-J2 cells when compared to laboratory constructs. The reason for such a difference in binding was unclear and was not investigated. However, it is possible that fimbria are expressed in greater abundance on the wild-type strains compared to laboratory constructs. Another possibility is that there are other fimbriae or non-fimbrial adhesins involved in binding that vary in their presence among laboratory constructs and wild-type strains. Two different wildtype K88ac strains, 3030-2 and 2534-86, bound to all the three cell lines efficiently, supporting the reproducibility of the adherence assays and cell culture models. Recent studies from our laboratory have suggested that LT contributes to the colonization of K88+ strains in the intestines of piglets (Berberov et al., 2004; Zhang et al., 2006). ETEC K88ac strain 1836-2 which lacks LT and ST did not adhere efficiently to IPEC-J2 cells when compared to wildtype strain 3030-2. In contrast, ETEC 3030-2 and 1836-2 bound equally to IPEC-1 cells. ETEC K88ac strain 2534-86 and its LT- mutant (MUN285) bound to both porcine cell types with equal efficiencies. Therefore, further investigations are required to clarify the role of LT, if any in bacterial adherence. In this study, F18 ETEC strain 2134 bound to IPEC-1 cells but not to IPEC-J2 cells. This indicated that IPEC-1 cells might represent a suitable in vitro cellular model for studying the pathogenesis of F18 ETEC. To our knowledge, no other porcine intestinal epithelial cell line susceptible to ETEC F18 has been described. When polarized IPEC-J2 cells were used, the same $E$. coli binding patterns and intensities were displayed as observed with non-polarized cells suggesting that both non-polarized and polar- ized porcine intestinal cells are equally suitable for in vitro ETEC studies.

Each antigenic variant of K88, namely K88ab, $\mathrm{K} 88 \mathrm{ac}$ and K88ad, exhibits a unique specificity to host receptors and various sugars are involved in the binding of different K88 variants to host receptors (Francis et al., 1999; Jin and Zhao, 2000). Based on the phenotypic diversity of binding of three antigenic variants of K88 ETEC, six different phenotypes (A-E) of pigs have been described (Baker et al., 1997; Bijlsma et al., 1982). As both IPEC-J2 and IPEC-1 cells bound to all three antigenic variants of K88, both cell lines were probably derived from phenotype A pigs.

In summary, this study demonstrates that various porcine ETEC strains bind to IPEC-J2 and IPEC-1 in greater abundance than to INT-407 cells and both IPEC-J2 and IPEC-1 cells provide a biologically relevant in vitro model system for studying porcine ETEC-host intestinal epithelial cell interactions.

\section{Acknowledgments}

Financial support for this study was provided by the SDSU Research Support Fund 2005 and the SDSU Agricultural Experiment Station. Student support was from SDSU Center for Infectious Disease and Vaccinology (CIDRV) and partial funding was from South Dakota NSF EPSCoR program. This manuscript is published as South Dakota Agricultural Experiment Station (AES) Journal series number 3614. We thank Dr. Bruce D. Schultz, Kansas State University, and Dr. Anthony Blikslager, North Carolina State University, for providing IPEC-J2 and IPEC-1 cells respectively for this study and Dong $\mathrm{He}$ for assistance with microscopy.

\section{References}

Baker et al., 1997 - D. R. Baker, L. O. Billey, and D. H. Francis, Distribution of K88 Escherichia coli-adhesive and nonadhesive phenotypes among pigs of four breeds, Vet. Microbiol. 54 (1997), pp. 123-132.

Bakker et al., 1992 - D. Bakker, P. T. Willemsen, L. H. Simons, F. G. van Zijderveld, and F. K. de Graaf, Characterization of the antigenic and adhesive properties of FaeG, the major subunit of K88 fimbriae, Mol. Microbiol. 6 (1992), pp. 247-255.

Berberov et al., 2004 - E. M. Berberov, Y. Zhou, D. H. Francis, M. A. Scott, S. D. Kachman, and R. ,A. Moxley, Relative importance of heat-labile enterotoxin in the causation of severe diarrheal disease in the gnotobiotic piglet model by a strain of enterotoxigenic Escherichia coli that produces multiple enterotoxins, Infect. Immun. 72 (2004), pp. 3914-3924.

Bijlsma et al., 1982 - I. G. Bijlsma, A. de Nijs, C. van der Meer, and J. F. Frik, Different pig phenotypes affect adherence of Escherichia coli to jejunal brush borders by 
K88ab, K88ac, or K88ad antigen, Infect. Immun. 37 (1982), pp. 891-894.

Casey et al., 1992 - T. A. Casey, B. Nagy, and H. W. Moon, Pathogenicity of porcine enterotoxigenic Escherichia coli that do not express K88, K99, F41, or $987 \mathrm{P}$ adhesins, Am. J. Vet. Res. 53 (1992), pp. 1488-1492.

Evans et al., 1979 - D. J. Evans Jr., D. G. Evans, and H. L. DuPont, Hemagglutination patterns of enterotoxigenic and enteropathogenic Escherichia coli determined with human, bovine, chicken, and guinea pig erythrocytes in the presence and absence of mannose, Infect. Immun. 23 (1979), pp. 336-346.

Fairbrother et al., 2005 - J. M. Fairbrother, E. Nadeau, and C. L. Gyles, Escherichia coli in postweaning diarrhea in pigs: an update on bacterial types, pathogenesis, and prevention strategies, Anim. Health Res. Rev. 6 (2005), pp. 17-39.

Francis et al., 1986 - D. H. Francis, J. E. Collins, and J. R. Duimstra, Infection of gnotobiotic pigs with an Escherichia coli $\mathrm{O}_{157: \mathrm{H}_{7}}$ strain associated with an outbreak of hemorrhagic colitis, Infect. Immun. 51 (1986), pp. 953-956.

Francis et al., 1999 - D. H. Francis, A. K. Erickson, and P. A. Grange, K88 adhesins of enterotoxigenic Escherichia coli and their porcine enterocyte receptors, Adv. Exp. Med. Biol. 473 (1999), pp. 147-154.

Francis et al., 1998 - D. H. Francis, P. A. Grange, D. H. Zeman, D. R. Baker, R. Sun, and A. K. Erickson, Expression of mucin-type glycoprotein K88 receptors strongly correlates with piglet susceptibility to K88(+) enterotoxigenic Escherichia coli, but adhesion of this bacterium to brush borders does not, Infect. Immun. 66 (1998), pp. 4050-4055.

Francis et al., 1982 - D. H. Francis, G. A. Remmers, and P. S. DeZeeuw, Production of K88, K99, and 987P antigens by Escherichia coli cultured on synthetic and complex media, J. Clin. Microbiol. 15 (1982), pp. 181-183.

Francis and Willgohs, 1991 - D. H. Francis and J. A. Willgohs, Evaluation of a live avirulent Escherichia coli vaccine for $\mathrm{K} 88+$, LT+ enterotoxigenic colibacillosis in weaned pigs, Am. J. Vet. Res. 52 (1991), pp. 1051-1055.

Gaastra and Pederson, 1986 - W. Gaastra and P. A. Pederson, Serologic variants of the K88 antigen. In: D. L. Lark and S. Normark, Editors, Protein-Carbohydrate Interactions in Biological Systems, Academic Press. Inc., London (1986).

Imberechts et al., 1996 - H. Imberechts, P. Wild, G. Charlier, H. De Greve, P. Lintermans, and P. Pohl, Characterization of F18 fimbrial genes fedE and fedF involved in adhesion and length of enterotoxemic Escherichia coli strain 107/86, Microb. Pathog. 21 (1996), pp. 183-192.

Isaacson et al., 1978 - R. E. Isaacson, P. C. Fusco, C. C. Brinton, and H. W. Moon, In vitro adhesion of Escherichia coli to porcine small intestinal epithelial cells: pili as adhesive factors, Infect. Immun. 21 (1978), pp. 392-397.

Jin and Zhao, $2000-$ L. Z. Jin and X. Zhao, Intestinal receptors for adhesive fimbriae of enterotoxigenic Escherichia coli (ETEC) K88 in swine-a review, Appl. Microbiol. Biotechnol. 54 (2000), pp. 311-318.

Jones and Rutter, 1972 - G. W. Jones and J. M. Rutter, Role of the K88 antigen in the pathogenesis of neonatal diarrhea caused by Escherichia coli in piglets, Infect. Immun. 6 (1972), pp. 918-927.
Knutton et al., 1984 - S. Knutton, D. R. Lloyd, D. C. Candy, and A. S. McNeish, In vitro adhesion of enterotoxigenic Escherichia coli to human intestinal epithelial cells from mucosal biopsies, Infect. Immun. 44 (1984), pp. 514-518.

Lu et al., 2002 - S. Lu, Y. Yao, S. Meng, X. Cheng, and D. D. Black, Overexpression of apolipoprotein A-IV enhances lipid transport in newborn swine intestinal epithelial cells, J. Biol. Chem. 277 (2002), pp. 31929-31937.

Moon et al., 1977 - H. W. Moon, B. Nagy, R. E. Isaacson, and I. Orskov, Occurrence of K99 antigen on Escherichia coli isolated from pigs and colonization of pig ileum by K99+ enterotoxigenic E. coli from calves and pigs, Infect. Immun. 15 (1977), pp. 614-620.

Moon et al., 1968 - H. W. Moon, D. K. Sorensen. and J. H. Sautter, Experimental enteric colibacillosis in piglets, Can. J. Comp. Med. 32 (1968), pp. 493-497.

Morris et al., 1982 - J. A. Morris, C. Thorns, A. C. Scott, W. J. Sojka. and G. A. Wells, Adhesion in vitro and in vivo associated with an adhesive antigen (F41) produced by a K99 mutant of the reference strain Escherichia coli B41, Infect. Immun. 36 (1982), pp. 1146-1153.

Moxley et al., 1998 - R. A. Moxley, E. M. Berberov, D. H. Francis, J. Xing, M. Moayeri, R. A. Welch, D. R. Baker. and R. G. Barletta, Pathogenicity of an enterotoxigenic Escherichia coli hemolysin (hlyA) mutant in gnotobiotic piglets, Infect. Immun. 66 (1998), pp. 5031-5035.

Mullaney et al., 1991 - C. D. Mullaney, D. H. Francis. and J. A. Willgohs, Comparison of seroagglutination, ELISA, and indirect fluorescent antibody staining for the detection of K99, K88, and 987P pilus antigens of Escherichia coli, J. Vet. Diagn. Invest. 3 (1991), pp. 115-118.

Nagy and Fekete, 2005 - B. Nagy and P. Z. Fekete, Enterotoxigenic Escherichia coli in veterinary medicine, Int. J. Med. Microbiol. 295 (2005), pp. 443-454.

Orskov et al., 1975 - I. Orskov, F. Orskov, H. W. Smith, and W. J. Sojka, The establishment of K99, a thermolabile, transmissible Escherichia coli $\mathrm{K}$ antigen, previously called "Kco", possessed by calf and lamb enteropathogenic strains, Acta Pathol. Microbiol. Scand. [B] 83 (1975), pp. 31-36.

Roselli et al., 2006 - M. Roselli, A. Finamore, M. S. Britti, and E. Mengheri, Probiotic bacteria Bifidobacterium animalis MB5 and Lactobacillus rhamnosus GG protect intestinal Caco-2 cells from the inflammation-associated response induced by enterotoxigenic Escherichia coli K88, Br. J. Nutr. 95 (2006), pp. 1177-1184.

Sambrook et al., 2001 - J. Sambrook, P. MacCallum, and D. Russell, Molecular Cloning: A Laboratory Manual (third ed.), Cold Spring Harbor Laboratory Press, Cold Spring Harbor, USA (2001).

Schierack et al., 2006 - P. Schierack, M. Nordhoff, M. Pollmann, K. D. Weyrauch, S. Amasheh, U. Lodemann, J. Jores, B. Tachu, S. Kleta, A. Blikslager, K. Tedin, and L. H. Wieler, Characterization of a porcine intestinal epithelial cell line for in vitro studies of microbial pathogenesis in swine, Histochem. Cell. Biol. 125 (2006), pp. 293-305.

Zhang et al., 2006 - W. Zhang, E. M. Berberov, J. Freeling, D. He, R. A. Moxley, and D. H. Francis, Significance of heat-stable and heat-labile enterotoxins in porcine colibacillosis in an additive model for pathogenicity studies, Infect. Immun. 74 (2006), pp. 3107-3114. 